\title{
BMJ Open Body mass index variation over time and associated factors among HIV- positive adults on second-line ART in north-west Ethiopia: a retrospective follow-up study
}

Adhanom Gebreegziabher Baraki, ${ }^{\circledR}$ Lemma Derseh Gezie, ${ }^{\odot}$ Ejigu Gebeye Zeleke, Tadesse Awoke, Adino Tesfahun Tsegaye

To cite: Baraki AG, Gezie LD, Zeleke EG, et al. Body mass index variation over time and associated factors among HIV-positive adults on second-line ART in northwest Ethiopia: a retrospective follow-up study. BMJ Open 2019;9:e033393. doi:10.1136/ bmjopen-2019-033393

- Prepublication history for this paper is available online. To view these files, please visit the journal online (http://dx.doi.org/ 10.1136bmjopen-2019-033393)

Received 02 August 2019 Revised 28 August 2019 Accepted 30 August 2019
Check for updates

(C) Author(s) (or their employer(s)) 2019. Re-use permitted under CC BY-NC. No commercial re-use. See rights and permissions. Published by BMJ.

Epidemiology and Biostatistics, Institute of Public Health,

College of Medicine and Health Sciences, University of Gondar, Gondar, Ethiopia

Correspondence to Mr Adhanom Gebreegziabher Baraki; adsh04@gmail.com

\section{ABSTRACT}

Objectives This study aimed to assess the evolution of body mass index (BMI) of HIV-positive adults on secondline antiretroviral therapy (ART) over time and factors affecting it in north-west Ethiopia.

Design An institution-based retrospective follow-up study was conducted using data extracted from 1016 patient cards from February 2008 to February 2016.

Setting Eight referral hospitals from Amhara region, Ethiopia were included.

Participants HIV patients who started second-line ART. Outcome measures Change in BMI since starting second-line ART.

Results Five hundred and thirty-eight (52.95\%) participants were males and the median age of the participants was 33 years (IQR: 28; 39). The median follow-up time was 18 months (IQR: 5.2; 32.2). The average change of BMI showed linear increase over time. The amount of BMl increment or decrement according to each variable was shown as $\beta$ coefficients. Treatment duration ( $\beta=0.013,95 \% \mathrm{Cl} 0.004$ to 0.022 ), isoniazid prophylaxis ( $\beta=0.87,95 \% \mathrm{Cl} 0.32$ to 1.42 ), cotrimoxazole prophylaxis ( $\beta=0.63,95 \% \mathrm{Cl} 0.08$ to 1.19$)$, ambulatory functional status $(\beta=-1.16,95 \% \mathrm{Cl}-1.95$ to 1.31$)$, bedridden functional status $(\beta=-1.83,95 \% \mathrm{Cl}-2.47$ to 1.21), WHO stage III $(\beta=-0.42,95 \% \mathrm{Cl}-0.65$ to 0.20$)$, WHO stage IV ( $\beta=-0.62,95 \% \mathrm{Cl}-1.02$ to 0.22$)$, CD4 count ( $\beta=0.001,95 \% \mathrm{Cl} 0.0008$ to 0.0015$)$, and time interaction of variables like tertiary educational status $(\beta=0.02$, $95 \% \mathrm{Cl} 0.01$ to 0.04 ), ambulatory functional status $(\beta=0.03,95 \% \mathrm{Cl} 0.01$ to 0.05$)$ and WHO stages III $(\beta=0.01$, $95 \% \mathrm{Cl} 0.007$ to 0.02 ) were found to be significant predictors.

Conclusion The BMl of patients has shown linear increment over the treatment time. Factors affecting it have been identified but its effect on cardiovascular disease needs further study.

\section{BACKGROUND}

HIV has continued to be a major global public health problem, having killed more than 35 million lives so far. In 2017, 940000 people died from HIV-related causes globally. ${ }^{1}$
Strengths and limitations of this study

- Being a retrospective study, this study shares the limitations of secondary data collection; as a result, we were unable to find some predictors like viral load, alcohol consumption, smoking and nutritional history.

- The study is not based only on patient cards that started the second-line antiretroviral therapy at the same point in time; also the length of the follow-up period for each participant was not equal across all participants.

- The method of data anaysis ensures a valid estimate by handling data that are measured at different time periods and has missing values.

- The large number of measurements will again strengthen the precision of the estimates.

According to the Ethiopia Demographic and Health Survey of 2016, the adult prevalence of HIV in Ethiopia was $0.9 \% .^{2}$ Death due to HIV/AIDS has enormously decreased due to the introduction of antiretroviral therapy (ART) and millions of people are currently accessing it. ${ }^{3}$

The body weight of patients with HIV has been an important diagnostic and evaluation measure. Low body mass index (BMI) is recognised as one of the first criteria for the clinical definition of AIDS. The current WHO clinical staging of the disease also includes moderate unexplained weight loss $(<10 \%$ presumed or measured body weight, stage 2), unexplained severe weight loss ( $>10 \%$ of body weight or BMI $\leq 18.5 \mathrm{~kg} / \mathrm{m}^{2}$, clinical stage 3) and HIV wasting syndrome (unexplained severe wasting, clinical stage 4) as criteria to define advanced HIV infection. ${ }^{4}$

The BMI of patients with HIV is an important predictor of ART outcome, ${ }^{5-8}$ 
including the prediction of the CD4 cells change ${ }^{9}$ and death. ${ }^{10-12}$ A negative change in BMI of patients was also found to be an independent predictor of dropout from HIV care. $^{13}$

The BMI of patients with HIV is affected by gender, ${ }^{14}$ duration of treatment, ${ }^{101516}$ isoniazid prophylaxis therapy (IPT) and cotrimoxazole prophylaxis therapy (CPT),${ }^{17} 18$ WHO stage ${ }^{14}$ and CD4 count. ${ }^{15} 19$

This study focused on patients on second-line ART mainly because there is no much option for physicians to choose from if this therapy fails. BMI evolution is a very important and easily calculable tool that can predict treatment outcome, dropout from treatment, CD4 recovery and death, but literature about its evolution across treatment time and factors affecting it is limited. Therefore this study tried to fill this information gap by determining the BMI evolution over treatment time and identifying the key factors affecting it. The information generated by this study will contribute to monitoring the response of patients for ART.

\section{METHOD AND MATERIALS \\ Study design and period}

An institution-based retrospective follow-up study was conducted among adults, aged 24 years and above, who started second-line ART from February 2008 to February 2016

\section{Study area and population}

The study was conducted in Amhara regional state which is one of the nine administrative regions and two city councils of Ethiopia. The region constitutes majority of ART users in the country. The study population was adult HIV-infected patients on second-line ART in all the nine referral hospitals of the region. The first-line treatment consisted of a combination of two nucleoside/nucleotide reverse transcriptase inhibitors (NRTI) with one non-nucleoside reverse transcriptase inhibitor. In case of failure of first-line treatment, a second-line treatment was implemented, using two NRTIs not previously used in first-line treatment, as well as one additional protease inhibitor.

\section{Sample size and sampling procedure}

All patients with HIV who initiated second-line therapy $(n=1233)$ between February 2008 and 2016 were included. But only 1016 patients who had two or more measurements of weight were included in the study.

\section{Data collection procedures}

A data extraction checklist was prepared and the data were collected from registration cards of patients with HIV. Data about the baseline weight and height of patients and other factors like sociodemographic, clinical and treatment related factors were also collected from the registration card of each patient with HIV. Adherence to ART was assessed by pill counts at visits and was recorded as 'GOOD' ( $\geq 95 \%$ adherence), 'FAIR' ( $80 \%-95 \%$ adherence) or 'POOR' ( $<80 \%$ adherence) ${ }^{20}$

\section{Data structure, compilation and analysis strategy}

The data were cleaned and entered into EPI info V.7 and analysed using STATA V.14.0. The BMI of patients with HIV was computed by dividing the weight of patients in kilograms $(\mathrm{kg})$ that was recorded during each follow-up visit, by their baseline height in metre squared. Exploratory data analysis for the weight of patients including individual profile plot, mean profile plot, and descriptive and summary statistics were done. To determine the factors associated with BMI of patients, bivariable analysis for each independent variable was assessed and those found to be significant $(p<0.25)$ were selected for the multivariable analysis. The need for random intercept and random slope was checked by the likelihood ratio (LR) test. Since we cannot ignore the repeated measurements that have between-individual variation and within-individual variation, ${ }^{21}$ a linear mixed-effect model with random intercept and random slope was fitted.

\section{Patient and public involvement}

Since we have used secondary data/chart review, patients or the public were not involved during identifying the research question or the design and conduct of the study.

\section{RESULTS}

\section{Patient characteristics}

We had a total of 1016 adult patients who were taking second-line ART. Of the total, 538 (52.95\%) were male. All participants were 24 years of age or older with a median age of 33 years (IQR: 28; 39). A large proportion of these patients, $370(37.1 \%)$, was unemployed and 371 $(36.9 \%)$ had attended secondary school.

The median follow-up time was 18 months (IQR: 5.2; 32.2). There were a maximum of 12 and a minimum of 2 measurements of weight per patient. Almost all visits were not balanced in their time of measurements. The median time between each weight measurement is reported as median (IQR) as follows: $6.7(4.27,10.03), 6.08(4.14,9)$, 6.13 (4.2, 8.9), $6.27(4.53,8.9), 5.9$ (3.97, 7.79), 5.83 (3.7, 8.13), 5.45 (3.37, 7.43), 4.86 (2.97, 6.2), 5.19 (3, 7.37), 5.97 $(4.23,7.04), 5.55(2.83,5.86)$ and $3(0.9,4.84)$ months from the first to the twelfth weight measurement, respectively.

At the initiation of second-line ART majority of the participants, 393 (45.54\%), were at WHO stage I and 324 $(37.54 \%)$ were at WHO stage III. A large proportion of the participants, 871 (86\%), had working functional status at baseline, the rest, $114(11.25 \%)$ and $28(2.75 \%)$, were ambulatory and bedridden, respectively. The median CD4 count was 253 (IQR: 147; 399). IPT and CPT were given for $247(24.87 \%)$ and $256(25.65 \%)$ participants, respectively (table 1 ).

\section{EXPLORATORY DATA ANALYSIS}

At baseline a total of $391(38.5 \%)$ patients had BMI $<18.5 \mathrm{~kg} / \mathrm{m}^{2}$ whereas $549(54 \%), 64(6.3 \%)$ and $12(1.2 \%)$ 
Table 1 Baseline sociodemographic and baseline characteristics of adult patients with HIV on ART in Amhara region, 2008-2016

\begin{tabular}{|c|c|c|}
\hline Variables & Frequency & Percentage \\
\hline \multicolumn{3}{|l|}{ Age, years } \\
\hline 25-34 & 547 & 53.89 \\
\hline $35-44$ & 333 & 32.81 \\
\hline $45-54$ & 104 & 10.25 \\
\hline $55-64$ & 26 & 2.56 \\
\hline$>65$ & 6 & 0.59 \\
\hline \multicolumn{3}{|l|}{ Sex } \\
\hline Female & 478 & 47.05 \\
\hline Male & 538 & 52.95 \\
\hline \multicolumn{3}{|l|}{ Educational status } \\
\hline No education & 315 & 31.34 \\
\hline Primary education & 201 & 20.00 \\
\hline Secondary education & 371 & 36.92 \\
\hline Tertiary education & 118 & 11.74 \\
\hline Missing & 11 & 0.01 \\
\hline \multicolumn{3}{|l|}{ Occupation } \\
\hline Unemployed & 370 & 36.42 \\
\hline Governmental & 286 & 28.15 \\
\hline Non-governmental & 21 & 2.06 \\
\hline Private & 66 & 6.50 \\
\hline Daily labourers & 254 & 25.00 \\
\hline Missing & 19 & 1.87 \\
\hline \multicolumn{3}{|l|}{ WHO stages } \\
\hline Stage I & 393 & 45.54 \\
\hline Stage II & 66 & 7.65 \\
\hline Stage III & 324 & 37.54 \\
\hline Stage IV & 80 & 9.27 \\
\hline \multicolumn{3}{|l|}{ Functional status } \\
\hline Working & 871 & 86 \\
\hline Ambulatory & 114 & 11.25 \\
\hline Bedridden & 28 & 2.75 \\
\hline \multicolumn{3}{|l|}{ CPT given } \\
\hline No & 742 & 74.35 \\
\hline Yes & 256 & 25.65 \\
\hline \multicolumn{3}{|l|}{ INH given } \\
\hline No & 746 & 75.13 \\
\hline Yes & 247 & 24.87 \\
\hline
\end{tabular}

ART, antiretroviral therapy; CPT, cotrimoxazole prophylaxis therapy; INH, isoniazid.

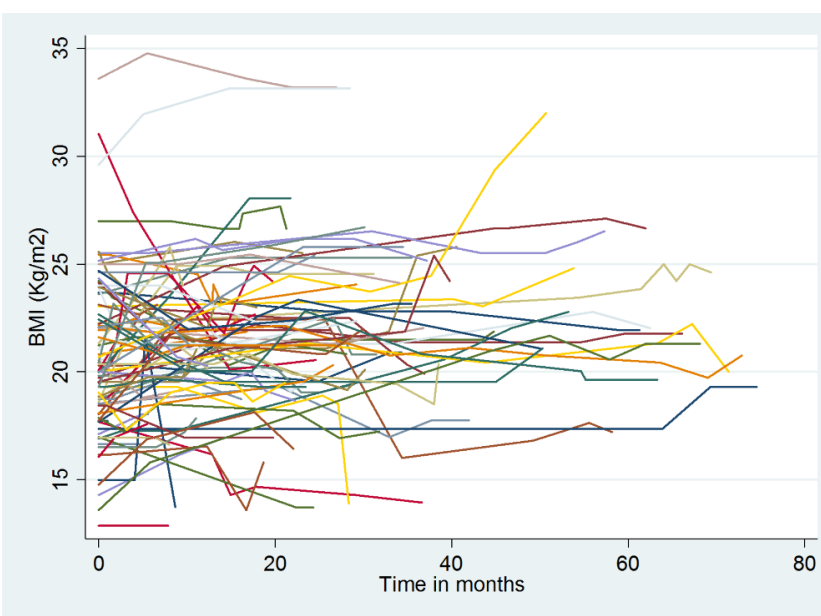

Figure 1 Individual profile plot of body mass index (BMI) over time for the first 100 individuals on second-line antiretroviral therapy (ART) in Amhara region, 2008-2016

had BMI $18.5-24.9 \mathrm{~kg} / \mathrm{m}^{2}, 25-29.9 \mathrm{~kg} / \mathrm{m}^{2}$ and $\geq 30 \mathrm{~kg} / \mathrm{m}^{2}$, respectively.

\section{Individual profile}

The average BMI of patients at baseline was $19.03 \mathrm{~kg} /$ $\mathrm{m}^{2}\left(\mathrm{SD}=3.6 \mathrm{~kg} / \mathrm{m}^{2}\right)$. The minimum and maximum BMIs were $8.33 \mathrm{~kg} / \mathrm{m}^{2}$ and $33.59 \mathrm{~kg} / \mathrm{m}^{2}$, respectively. Before proceeding to the formal statistical analysis we have described the data by exploring how individuals' BMIs change over time. To make the individual profile plot more informative and understandable, we have prepared it for the first 100 individuals (figure 1).

As we can see from this plot, the BMI status of patients has high variability within an individual over time and among individuals at baseline and also through time. Therefore to fit the data which have variability in the intercept and slope of trajectories very well, we have used a mixed model.

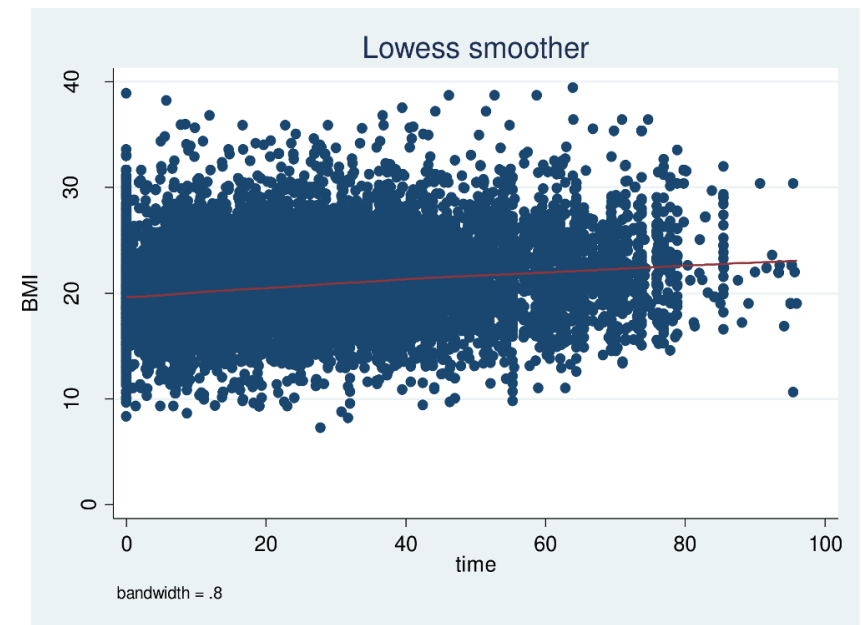

Figure 2 Time plot of body mass index (BMI) versus treatment time in months with LOWESS smoothed curve superimposed for patients with HIV on second-line antiretroviral therapy (ART) in Amhara region, 2008-2016. 
Table 2 Correlation structure checking and mode comparison

\begin{tabular}{llll}
\hline & Unstructured & Identity & Exchangeable \\
\hline AIC & 14337.93 & 17775.34 & 17666.17 \\
BIC & 14531.08 & 17956.02 & 17853.09 \\
\hline
\end{tabular}

AIC, Akaike Information Criteria; BIC, Bayesian Information criteria.

\section{Exploring the mean profile}

As stated above, all measurements in the data have no similar time of measurements, therefore, we have used locally weighted scatterplot smoothing (LOWESS) to determine BMI evolution over time (figure 2).

As one can easily understand from the mean profile plot, the BMI of these patients showed a linear increment over the treatment time.

\section{Modelling the BMI}

\section{Correlation structure checking and model comparison}

Comparing with Akaike information criteria (AIC), the correlation structure with the lowest AIC was chosen, in this case the unstructured correlation structure (table 2).

The need for random slope and intercept was checked by the likelihood ratio test of a model without a random intercept, a model with only random intercept and a model with both random intercept and slope (table 3 ).

So as we can see from the table 3 the inclusion of random intercept and random slope is reasonable, so in the final model we have used both random intercept and random slope.

\section{Factors affecting BMI evolution over time}

Based on the multivariable linear mixed-effects regression output: time since the start of second-line ART, IPT, CPT, functional status, WHO stage of the disease; and time interaction of categorical variables like educational status, functional status and WHO stages were found to be significant predictors of the BMI evolution of patients with HIV on second-line ART.

Keeping all the other variables constant, for a 1-month increment in treatment duration, the BMI of a patient increases by $0.013 \mathrm{~kg} / \mathrm{m}^{2}$. But specifically individuals who have tertiary level of education, ambulatory functional status and who are at WHO stage III have additional $0.02 \mathrm{~kg} / \mathrm{m}^{2}, 0.03 \mathrm{~kg} / \mathrm{m}^{2}$ and $0.01 \mathrm{~kg} / \mathrm{m}^{2}$ increment, respectively, in their BMI for a 1-month increment in the duration of treatment.

Taking IPT and CPT increases BMI by $0.87 \mathrm{~kg} / \mathrm{m}^{2}$ and $0.63 \mathrm{~kg} / \mathrm{m}^{2}$, respectively, as compared with their counterparts. Non-governmental organisation employment was

Table 3 Comparison of random effects models

\begin{tabular}{lrl}
\hline Random effects & LR $\chi^{2}$ & P value \\
\hline Model 1 intercept & 5625.28 & 0.0000 \\
Model 2 intercept, time & 297.13 & 0.0000 \\
\hline
\end{tabular}

associated with a $2.02 \mathrm{~kg} / \mathrm{m}^{2}$ increment when compared with government employment. Patients who are ambulatory and bedridden in their functional status have a $1.16 \mathrm{~kg} / \mathrm{m}^{2}$ and $1.83 \mathrm{~kg} / \mathrm{m}^{2}$ decrement in their BMI, respectively, as compared with those who have working functional status. Patients who are at WHO stage III and WHO stage IV have decreased BMI by $0.42 \mathrm{~kg} / \mathrm{m}^{2}$ and $0.62 \mathrm{~kg} / \mathrm{m}^{2}$, respectively, when compared with those who are at WHO stage I. For a unit cell $/ \mathrm{mm}^{3}$ increase in the CD4 count of patients BMI was found to increase by a factor of $0.001 \mathrm{~kg} / \mathrm{m}^{2}$ (table 4 ).

\section{DISCUSSION}

This study has found a linear increment in BMI of patients over the duration of the treatment. There were BMI differences between subjects at baseline and during their progress over time.

Factors found to have a significant effect on the evolution of BMI over treatment time at a multivariable linear mixed-effects model were, second-line treatment duration, IPT, CPT, employment status, functional status of the patient, WHO stage and CD4 count. Time interaction of educational status, functional status and WHO stage were also significant predictors of BMI evolution.

For a 1-month increase in treatment duration the BMI of patients increases by $0.04 \mathrm{~kg} / \mathrm{m}^{2}$; this finding is in line with studies in South Africa, ${ }^{22}$ India $^{10}$ and USA. ${ }^{23}$ The weight gain could possibly be due to normal reversion of the weight loss associated with HIV or due to drug-related metabolic changes which include hyperlipidaemia, insulin resistance and diabetes. ${ }^{24}$

Patients who took IPT and CPT have increased BMI when compared with their respective counterparts. This finding is supported by other studies like a study conducted in Abidjan ${ }^{17}$ and multicentre controlled clinical trial in Africa. ${ }^{18}$ The main reason for this association could be the reduction of potentially disabling and wasting diseases like tuberculosis and other opportunistic infections by these prophylactic drugs. ${ }^{25}{ }^{26}$ Highly increased appetite by the prophylaxis could also be a possible explanation. ${ }^{27}$

Being ambulatory and bedridden decreases BMI when compared with those who are working. Since these individuals are not working they may not access a nutritious and balanced diet which affects their BMI. Another reason could be additionally decreased immunity caused by physical inactivity which makes them more susceptible to minor infections leading to higher calorie loss. ${ }^{28}$ These groups of people are also at a higher risk of diarrhoeal disease for they cannot take care of themselves which in turn causes weight loss. ${ }^{29}$

When compared with patients at WHO stage I, those at WHO stages III and IV have decreased BMI. This finding is in line with a multicentre study in resource-limited settings which shows individuals who had high clinical status (WHO stages III and IV) had poorer weight gain when compared with weight change in patients at lower 
Table 4 Parameter estimates for full linear mixed-effects model

\begin{tabular}{lllll}
\hline Characteristics & Coefficient & $\begin{array}{l}\text { Cl } \\
\text { Lower Upper }\end{array}$ & P value \\
\hline Intercept & 19.03 & 18.11 & 19.95 & 0.000 \\
Sex & & & & \\
Female & 0.00 & & & \\
Male & -0.01 & -0.51 & 0.48 & 0.956 \\
\hline Adherence & & & & \\
Poor & 0.00 & & & \\
Fair & 0.43 & -0.24 & 1.10 & 0.207 \\
\hline Good & 0.48 & -0.06 & 1.02 & 0.080 \\
$\begin{array}{l}\text { INH prophylaxis } \\
\text { given }\end{array}$ & & & & \\
No & 0.00 & & & \\
Yes & 0.87 & 0.32 & 1.42 & 0.002 \\
\hline
\end{tabular}

CPT prophylaxis

given

\begin{tabular}{|c|c|c|c|c|}
\hline No & 0.00 & & & \\
\hline Yes & 0.63 & 0.08 & 1.19 & 0.025 \\
\hline \multicolumn{5}{|l|}{ Educational status } \\
\hline Illiterate & 0.00 & & & \\
\hline Primary & -0.03 & -0.72 & 0.66 & 0.924 \\
\hline Secondary & 0.47 & -0.21 & 1.14 & 0.176 \\
\hline Tertiary & 0.94 & -0.01 & 1.89 & 0.051 \\
\hline \multicolumn{5}{|l|}{ Functional status } \\
\hline Working & 0.00 & & & \\
\hline Ambulatory & -1.16 & -1.95 & -1.31 & 0.000 \\
\hline Bedridden & -1.83 & -2.47 & -1.21 & 0.000 \\
\hline \multicolumn{5}{|l|}{ WHO stage } \\
\hline Stage I & 0.00 & & & \\
\hline Stage II & -0.06 & -0.45 & 0.33 & 0.760 \\
\hline Stage III & -0.42 & -0.65 & -0.20 & 0.000 \\
\hline Stage IV & -0.62 & -1.02 & -0.22 & 0.002 \\
\hline CD4 count & 0.001 & 0.0008 & 0.0015 & 0.000 \\
\hline Time on treatment & 0.013 & 0.004 & 0.022 & 0.005 \\
\hline \multicolumn{5}{|l|}{$\begin{array}{l}\text { Education status } \\
\times \text { time }\end{array}$} \\
\hline Illiterate $\times$ time & 0.00 & & & \\
\hline Primary $\times$ time & 0.002 & -0.01 & 0.015 & 0.801 \\
\hline Secondary $\times$ time & 0.01 & -0.003 & 0.019 & 0.162 \\
\hline Tertiary $\times$ time & 0.02 & 0.01 & 0.04 & 0.009 \\
\hline
\end{tabular}

Functional status

$x$ time

\begin{tabular}{lrrrl} 
Working $\times$ time & 0.00 & & & \\
Ambulatory $\times$ time & 0.03 & 0.01 & 0.05 & 0.000 \\
Bedridden $\times$ time & -0.01 & -0.05 & 0.02 & 0.49 \\
WHO stage $\times$ time & & & & \\
Stage I $\times$ time & 0.00 & & & \\
Stage II $\times$ time & 0.004 & -0.008 & 0.166 & 0.522 \\
\hline
\end{tabular}

Table 4 Continued

\begin{tabular}{lcccc}
\hline Characteristics & Coefficient & \multicolumn{4}{l}{ Lower Upper } & P value \\
\hline Stage III $\times$ time & 0.01 & 0.007 & 0.020 & 0.000 \\
Stage IV $\times$ time & -0.0003 & -0.016 & 0.016 & 0.969 \\
\hline
\end{tabular}

$\mathrm{CPT}$, cotrimoxazole prophylaxis; $\mathrm{INH}$, isoniazid.

WHO stage. ${ }^{14}$ The possible reason can be unexplained chronic diarrhoea and HIV enteropathy in these patients and the associated malabsorption ${ }^{4}$ or it could be due to fever of unknown origin in the late stage of the disease which results in an increased calorie loss and wasting. ${ }^{30}$

The BMI of patients was also found to increase with the increment in their $\mathrm{CD} 4$ count. This positive association is supported by evidence from a study conducted in Boston ${ }^{15}$ and Tanzania. ${ }^{19}$ This increment can be explained by the association of increment of CD4 count with good clinical changes like viral suppression, improved immunity and appetite, leading to increment in the BMI of patients. ${ }^{13}$

Being a retrospective study, this study has limitations of secondary data collection, as a result, we were unable to find some predictors like viral load, alcohol consumption, smoking, marital status and nutritional history. The data may also have errors in documenting weight among some measurements.

\section{CONCLUSION}

In this study, we have found a linear increment in the BMI of patients with HIV on second-line ART. There was a significant variation in BMI of patients at baseline and through ART treatment time. Duration of treatment, IPT, CPT, functional status, WHO stage of the disease, CD4 count and time interaction of categorical variables like educational status, functional status and WHO stages were found to be significant predictors. The positive change in the BMI of patients shows an encouraging trend because we know this has a positive impact on $\mathrm{CD} 4$ recovery, and decreases loss to follow-up and death. Clinicians must also consider the identified risk factors when they provide service to these patients.

Acknowledgements The authors thank the University of Gondar, Amhara regional health office and hospital administrative bodies, clinicians, data clerks and card room workers for their cooperation, and for permission to conduct the study.

Contributors AGB, LDG, EGZ, TA, ATT have actively participated during conception and design, acquisition of data, analysis, and interpretation of data. All authors have read and approved the final version of the manuscript.

Funding No funding was received.

Competing interests None declared.

Patient consent for publication Not required.

Ethics approval Ethical clearance was obtained from the Institutional Review Board of Institute of Public Health, University of Gondar. Names and unique ART numbers of patients were not collected to keep the privacy of patients during the data collection.

Provenance and peer review Not commissioned; externally peer reviewed. 
Data availability statement Data are available upon reasonable request.

Open access This is an open access article distributed in accordance with the Creative Commons Attribution Non Commercial (CC BY-NC 4.0) license, which permits others to distribute, remix, adapt, build upon this work non-commercially, and license their derivative works on different terms, provided the original work is properly cited, appropriate credit is given, any changes made indicated, and the use is non-commercial. See: http://creativecommons.org/licenses/by-nc/4.0/.

Author note Adhanom Gebreegziabher has a BSc degree in Public health as a background and second degree in Epidemiology and Biostatistics; now teaching Epidemiology, Research methodology and disease prevention and control courses in the University of Gondar, Ethiopia.

\section{REFERENCES}

1. World Health Organization. Hiv/Aids key facts, 2018. Available: http:// wwwwhoint/news-room/fact-sheets/detail/hiv-aids

2. Central statistical agency. Ethiopia demographic and health survey HIV prevalence report, 2016. Available: https://wwwdhsprogramcom/ pubs/pdf/FR328/FR328HIVpdf

3. Mahy M, Stover J, Stanecki K, et al. Estimating the impact of antiretroviral therapy: regional and global estimates of life-years gained among adults. Sex Transm Infect 2010;86 Suppl 2(Suppl 2):ii67-71.

4. World Health Organization. Interim who clinical staging of HIV/AIDS and HIV/AIDS case definitions for surveillance, African region, 2005. Available: http://wwwwhoint/hiv/pub/guidelines/clinicalstagingpdf

5. Tsegaye AT, Wubshet M, Awoke T, et al. Predictors of treatment failure on second-line antiretroviral therapy among adults in Northwest Ethiopia: a multicentre retrospective follow-up study. BMJ Open 2016;6:e012537.

6. Seyoum A, Ndlovu P, Zewotir T. Quasi-Poisson versus negative binomial regression models in identifying factors affecting initial CD4 cell count change due to antiretroviral therapy administered to HIV-positive adults in north-west Ethiopia (Amhara region). AIDS Res Ther 2016;13:36.

7. Patel D, Desai M, Shah AN, et al. Early outcome of second line antiretroviral therapy in treatment-experienced human immunodeficiency virus positive patients. Perspect Clin Res 2013;4:215-20.

8. Dalhatu I, Onotu D, Odafe S, et al. Outcomes of Nigeria's HIV/AIDS treatment program for patients initiated on antiretroviral treatment between 2004-2012. PLoS One 2016;11:e0165528.

9. Koethe JR, Jenkins CA, Lau B, et al. Body mass index and early CD4 T-cell recovery among adults initiating antiretroviral therapy in North America, 1998-2010. HIV Med 2015;16:572-7.

10. Chakravarty J, Sundar S, Chourasia A, et al. Outcome of patients on second line antiretroviral therapy under programmatic condition in India. BMC Infect Dis 2015;15:517.

11. Thao VP, Quang VM, Wolbers M, et al. Second-Line HIV therapy outcomes and determinants of mortality at the largest HIV referral center in southern Vietnam. Medicine 2015;94:e1715.

12. Swain PK, Grover G. Determination of predictors associated with HIVIAIDS patients using accelerated failure time model for interval censored survival data. , 2016: 6, 12-19.
13. Asiimwe SB, Kanyesigye M, Bwana B, et al. Predictors of dropout from care among HIV-infected patients initiating antiretroviral therapy at a public sector HIV treatment clinic in sub-Saharan Africa. BMC Infect Dis 2015;16:43.

14. Huisin 't Veld D, Balestre E, Buyze J, et al. Determinants of weight evolution among HIV-positive patients initiating antiretroviral treatment in low-resource settings. J Acquir Immune Defic Syndr 2015;70:146-54.

15. Mwamburi DM, Wilson IB, Jacobson DL, et al. Understanding the role of HIV load in determining weight change in the era of highly active antiretroviral therapy. Clin Infect Dis 2005;40:167-73.

16. Tang AM, Sheehan HB, Jordan MR, et al. Predictors of weight change in male HIV-positive injection drug users initiating antiretroviral therapy in Hanoi, Vietnam. AIDS Res Treat 2011;2011:1-8.

17. Guehi C, Badjé A, Gabillard D, et al. High prevalence of being Overweight and Obese HIV-infected persons, before and after 24 months on early ART in the ANRS 12136 Temprano Trial. AIDS Res Ther 2016;13:12

18. Haller L, Sossouhounto R, Coulibaly IM, et al. Isoniazid plus sulphadoxine-pyrimethamine can reduce morbidity of HIV-positive patients treated for tuberculosis in Africa: a controlled clinical trial. Chemotherapy 1999;45:452-65

19. Li N, Spiegelman D, Drain P, et al. Predictors of weight loss after HAART initiation among HIV-infected adults in Tanzania. AIDS 2012;26:577-85.

20. Ministry of Health. Federal Democratic Republic of Ethiopia. National guidelines for comprehensive HIV prevention, care and treatment, 2014.

21. Peng $\mathrm{H}$, Lu Y. Model selection in linear mixed effect models. $J$ Multivar Anal 2012;109:109-29.

22. Huis In 't Veld D, Pengpid S, Colebunders R, et al. Body mass index and waist circumference in patients with HIV in South Africa and associated socio-demographic, health related and psychosocial factors. AIDS Behav 2017.

23. Crum-Cianflone N, Roediger MP, Eberly L, et al. Increasing rates of obesity among HIV-infected persons during the HIV epidemic. PLOS One 2010;5:e10106.

24. Montessori V, Press N, Harris M, et al. Adverse effects of antiretroviral therapy for HIV infection. CMAJ : Canadian Medical Association Journal 2004;170:229-38.

25. Dowdy DW, Golub JE, Saraceni V, et al. Impact of isoniazid preventive therapy for HIV-infected adults in Rio de Janeiro, Brazil: an epidemiological model. J Acquir Immune Defic Syndr 2014;66:552-8

26. Mermin J, Lule J, Ekwaru JP, et al. Effect of co-trimoxazole prophylaxis on morbidity, mortality, CD4-cell count, and viral load in HIV infection in rural Uganda. The Lancet 2004;364:1428-34.

27. Mudie IS, Horne NW, Crofton JW. Isoniazid and weight gain. BMJ 1954:1:1304-5.

28. Nieman DC. Exercise, infection, and immunity. Int J Sports Med 1994;15 Suppl 3:S131-S141.

29. Katabira ET. Epidemiology and management of diarrheal disease in HIV infected patients. International Journal of Infectious Diseases 1999;3:164-7.

30. Hot A, Schmulewitz L, Viard J-P, et al. Fever of unknown origin in HIV/AIDS patients. Infect Dis Clin North Am 2007;21:1013-32. 